\title{
The Influence of the Pore Fluid on Desiccation of a Deformable Porous Material
}

\author{
H. Péron ${ }^{1}$, L.B. $\mathrm{Hu}^{2}$, T. Hueckel ${ }^{2}$, and L. Laloui ${ }^{1}$ \\ 1 Soil Mechanics Laboratory, Ecole Polytechnique Fédérale de Lausanne - EPFL, \\ Station 18, CH-1015 Lausanne, Switzerland \\ herve.peron@epfl.ch, lyesse.laloui@epfl.ch \\ 2 Department of Civil and Environmental Engineering, Duke University, Durham, \\ N.C. 27706, U.S.A. 1h19@duke.edu, hueckel@duke.edu
}

Summary. This paper aims at elucidating the influence of pore fluid properties on the shrinkage strains of deformable materials subjected to drying. Results of isothermal drying tests of two kinds of silts saturated with three different pore fluids are presented. Results show different strain amounts during drying and the final void ratios, depending on pore fluid. The rates of drying are consistent with saturated vapor pressures, while their amount with the surface tension. The shrinkage limit appears also to be controlled by a limitation in skeleton compressibility.

\section{Introduction}

The study of deformation due to drying is fundamental in the understanding of the patterns of stress generated by the constrained shrinkage and cracking in soils. When drying shrinkage is constrained, reaction forces arising located at the constraints generate stresses, which depend on the amount of shrinkage. Our previous papers (Péron et al. 2006, Hu et al. 2006) revealed how the development of such stress in the elastic domain leads to soil cracking.

Notably, several previous studies established that most of the desiccation shrinkage develops when soil is saturated (Croney and Coleman 1954, Fleureau et al. 1993). The state of full saturation when cracking initiates was hypothesized by several authors (Konrad and Ayad 1997, Abu-Hejleh and Znidarcic 1995, Lloret et al. 1998). Recently, Péron et al. (2006) showed that cracks occur at the end of saturation range or at the early stage of desaturation.

The goal in this work is to investigate a possible relationship between the total amount of shrinkage, its rate and the mechanisms of liquid removal and deformation. In particular, the role of the evaporation flux versus surface tension, in addition to soil compressibility and transport properties are of interest. Slow, constant humidity environment, (isothermal) air-drying of thin and long rectangular soil slabs was carried out. Two different soil types were

Page: 1 job: Peron macro: svmult.cls date/time: 26-Sep-2006/9:00 
used: clayey silt, and a powder of rock. The soils were wetted with three different pore fluids, characterized by distinctly different surface tension, latent heat, saturation vapor pressure and viscosity.

\section{Desiccation Tests}

\section{Desiccation Tests Procedure}

The silts employed were: a clayey silt (referred to as silt A), and a powder of granite (silt B). They were saturated with three fluids: tap water, and two alcohols: ethanol/water mixture (with a volume ratio of $50 \% / 50 \%$ ), and ethylene-glycol/water mixture $(65 \% / 35 \%)$ with the properties shown in Table 1. The two alcohols were used in mixtures with water to avoid flocculation, which is especially acute in pure ethanol. Saturation vapor pressure and latent heat were calculated as for pure mixtures.

Table 1. Properties of fluids used for material preparation

\begin{tabular}{llll}
\hline & \multicolumn{3}{c}{$\begin{array}{c}\text { Ethylene- } \\
\text { Plyce }\end{array}$} \\
& & $\begin{array}{l}\text { Ethanol } \\
\text { solution } \\
\text { solution }\end{array}$ \\
\hline Specific Latent Heat $\left[\mathrm{MJ} / \mathrm{m}^{3}\right]$ & 2448 & 1479 & 1591 \\
Saturation Vapor Pressure $[\mathrm{Pa}]$ & 2337 & 1639 & 3253 \\
Surface Tension $[\mathrm{mN} / \mathrm{m}]$ & 72.6 & $56.4^{a}$ & $30^{a}$ \\
Viscosity $\left[\mathrm{cm}^{2} / \mathrm{s}\right]$ & 0.01 & $0.0423^{b}$ & $0.029^{b}$ \\
Density $\left[\mathrm{g} / \mathrm{cm}^{3}\right]$ & 1 & 1.071 & 0.92 \\
\hline
\end{tabular}

${ }^{a}$ Vasquez et al. (1995) J Chem Eng Data 40;

Won et al. (1981) J Chem Eng Data 26

${ }^{b}$ Fernandez \& Quigley (1988) Can Geotech J 25;

Hayduk \& Malik (1971) J Chem Eng Data 16(2)

Two silts were used: a clayey silt (referred as silt A) and granite powder (silt B). Particles greater than $90 \mu \mathrm{m}$ (sandy fraction) have been removed. In silt $\mathrm{A}$, the clay fraction is $25 \%$; clay minerals are illite ( $10 \%$ of the total amount of mineral species), smectite $(10 \%)$ and chlorite (5\%). The liquid limit is $w_{L}=31.8 \%$, plastic limit $w_{P}=16.9 \%$, and the unit weight of solid particles is $\gamma_{s}=27.1 \mathrm{kN} / \mathrm{m}^{3}$. Silt B has low clay content (less than $7 \%$, mainly illite and chlorite). The liquid limit is $w_{L}=29.5 \%$, the plastic limit $w_{P}=20.1 \%$, and the unit weight of solid particles is $\gamma_{s}=27.7 \mathrm{kN} / \mathrm{m}^{3}$.

The tests were performed in a climate chamber with a controlled relative air humidity and temperature, of $40 \%$ and $18^{\circ} \mathrm{C}$, respectively. Strains in three directions were measured with calipers, which were fixed on the support. Average fluid content of the whole cake was recorded versus time by continually

Page: 2 job: Peron macro: svmult.cls date/time: 26-Sep-2006/9:00 
weighing an identical cake, dried in the same time in identical conditions as the one used for strain measurement. Details of the tests are reported elsewhere (Péron et al. 2006, Hu et al. 2007).

Density changes (due to the fact that the more volatile fluid of the mixture evaporates faster) were tested for the calculation of void ratio evolution during drying, as well as for the fluid properties determination.

\section{Desiccation Test Results}

The main result is the relationship between the void ratio evolution and the volumetric fluid content for both materials plotted in Fig. 1A and $\mathbf{B}$. In these graphs the thin dotted line denotes the theoretical void ratio evolution under the assumption that the material remains water saturated at constant volume of solids. It is noted that at the beginning of drying, all the curves do not much deviate from this line. However, well before all fluid is evaporated, the shrinkage stopped. The volumetric water content value at that point identified as the shrinkage limit tends to depend on the pore fluid. Void ratio stabilizes finally, reaching a "limiting void ratio." The curves obtained could be conceptualized as piecewise bilinear, with the first part merging with the saturation line, and a second part with void ratio equal to a constant "limiting void ratio."

For either silt, water involves the highest amount shrinkage and ethanol the lowest. Ethylene-glycol induces intermediate values, closer to water in the case of silt B, and closer to ethanol in the case of silt A. Shrinkage in the case of silt A was much more significant for all three liquids, than in the case of silt $\mathrm{B}$. The values of the limiting void ratios exhibit also an apparently wide scatter. In Figure 2 the volume loss of fluids for silt A and B has been plotted versus time. The drying of silt with glycol is significantly slower. The drying rates are well correlated with vapor pressure of the permeating liquid: the higher vapor pressure, the lower drying rate.
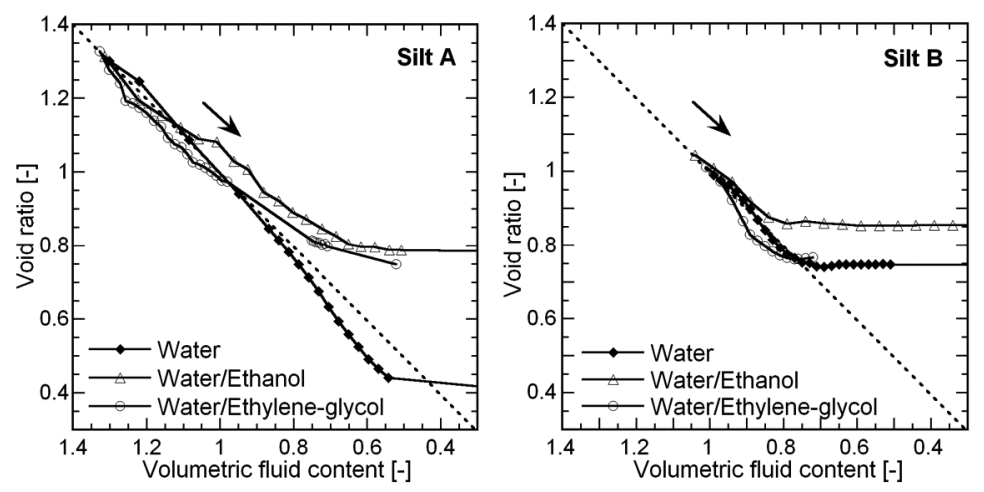

Fig. 1. Void ratio evolution with respect to volumetric fluid content 

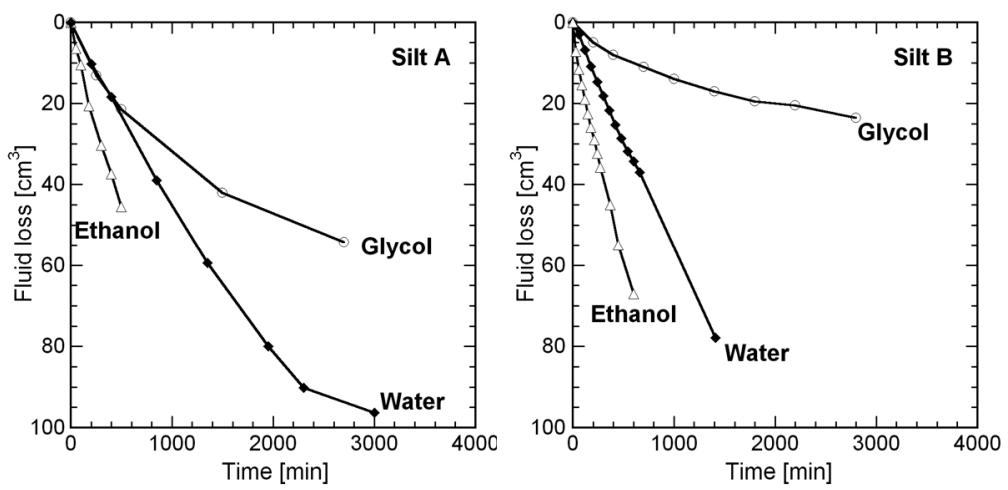

Fig. 2. Fluid loss with respect to time

\section{Discussion}

First, it has to be realized that the rates of fluid removal and void ratio change (Fig. 1 and Fig. 2) follow the order of saturated vapour pressure of the fluids, that is glycol - water - ethanol.

A hypothesis of air-water interface (or contractile skin) is described in Fredlund and Rahardjo (1993). The surface tension associated with the contractile skin results in a reaction force, which is likely to produce compression of the soil structure. For the saturated range, Hu et al. (2007) showed that evaporation at the external solid-fluid-air interface is the only driving force of shrinkage. Capillary force exists only at this boundary, as there is no air within the body of the sample. During drying the removal of the pore fluid at the boundary generates an outward transport of fluid, and a consequent fluid content decrease within the medium. That induces a negative pore pressure gradient across the body. That also produces strain and the proportional stress field that is equilibrated at the boundary by capillary forces. Hu et al. (2007) performed a simple numerical simulation of the process in 1D using Biot theory that captures the salient points of the process.

The limiting value of the void ratio change and the total strain variation over the course of drying are left outside of the above model. Shrinkage of unconstrained specimens ceases at a relatively well-defined configuration. The mechanism of this cessation remains an open question. At least for the silt A when wetted with water, the air entry value obtained from an independent evaluation via the water retention curve coincides with the shrinkage limit (see Péron et al. 2006). Nevertheless, in some cases, shrinkage limit may significantly differ from the air entry value; see experimental results of Taibi (1992) for remolded silt. Fleureau et al. (1993) hypothesise that for low saturation state, the capillary forces between the particles are normal to a plane tangent to the particle at the contact point and thus cannot result in a rearrangement of the soil structure. Other hypotheses on the shrinkage limit, include a locking 
value of compressive strain, air phase spreading due to either bulk pore water (internal) cavitation or an external air/fluid interface instability followed by fingering. In general, such hypotheses may be linked to the properties of the solid skeleton and of the fluid. In what follows we explore some numerical correlations between the limiting void ratio and void ratio variation during drying and basic fluid properties (surface tension, vapor pressure, latent heat, viscosity). Figures 3-6 present such correlations. The limiting void ratios and void ratio variation values are clearly different for the two materials. They also depend on the permeating fluid. Interestingly, the numerical values of the characteristics of interest for the fluid employed do not follow the same sequence.

For both soils, the value of limiting void ratio, as well as void ratio evolution exhibit similar trends with respect to viscosity, surface tension, saturation vapor pressure and latent heat. However, silt A is clearly more sensitive to pore liquid than silt B. Indeed, the differences in the values of limiting void ratio, as well as void ratio variation in silt B are not substantial. Visibly, the most clear monotonic trend of the void ratio variables is seen for surface tension (Fig. 6). The higher the surface tension the higher the total variation of void ratio and hence the volumetric strain during drying and the lower the
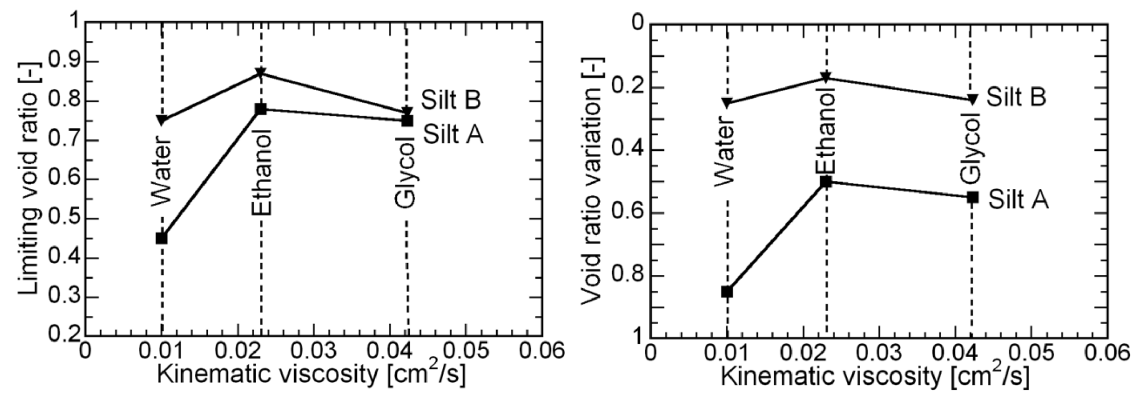

Fig. 3. Limiting void ratio and void ratio variation with respect to viscosity
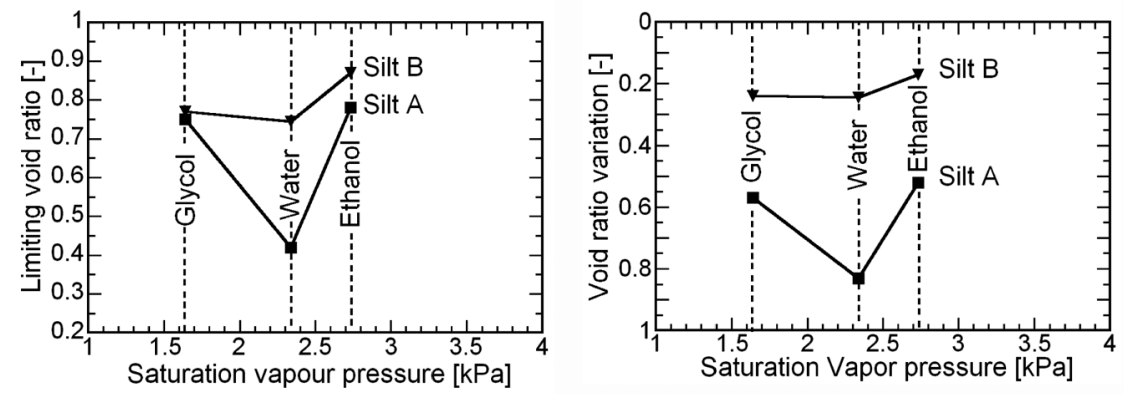

Fig. 4. Limiting void ratio and void ratio variation with respect to vapor pressure 

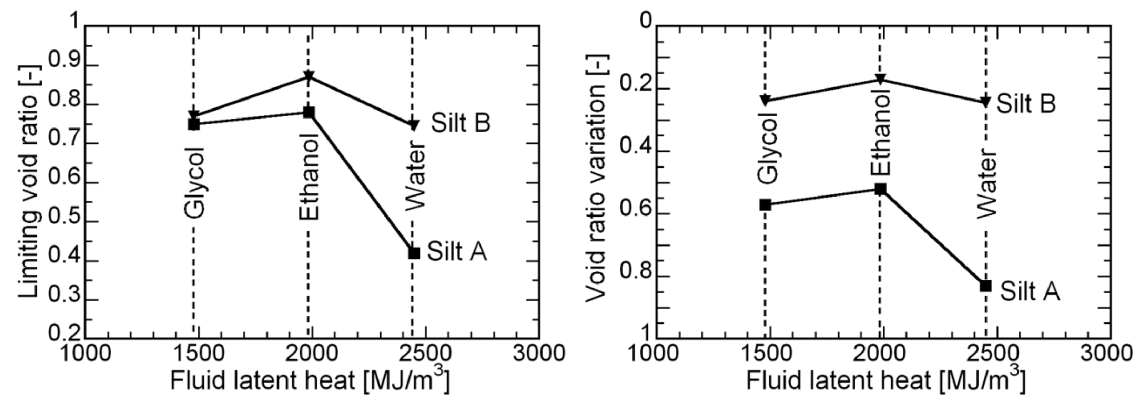

Fig. 5. Limiting void ratio and void ratio variation with respect to latent heat
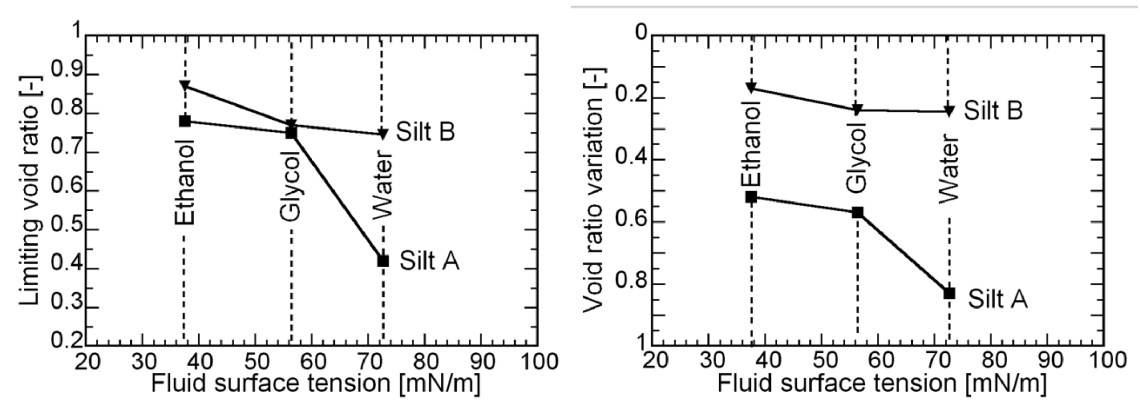

Fig. 6. Limiting void ratio and void ratio variation with respect to surface tension

limiting void ratio. Early research (Kingery and Francl 1954) assessed a similar trend and showed the final shrinkage of kaolinite clay during drying was a linear function of the surface tension of the pore fluid.

This observation supports the assumption that the shrinkage deformation is controlled by external boundary menisci, which act as a stretched membrane. It must be recognized however, that the capillary forces depend also on the contact angle, which however, is not known at the grain scale.

Viscosity, and hence permeability show much less influence except for a clear difference between the two alcohols and water in silt A (Fig. 3). As these two variables control the fluid flux to the external surface they may have a greater impact on the rate than the total or limiting strain.

Finally, it seems that the clayey character of silt A makes it much more shrinking with water than it is with alcohol as the pore fluid. Earlier tests of Sridharan and Venkatappa Rao (1973) indicate a dramatically lower compressibility of clayey soils permeated with alcohols than with water. This is attributed to the existence of highly deformable electric diffuse double layer coatings around clay particles in water. Hence, it appears that difference in response of soils to drying in terms of the total shrinkage and limiting void ratio point also to their difference in generating the adsorbed water. 


\section{Conclusions and Open Issues}

Drying of unconstrained slabs of silts has been tested experimentally. Most of the shrinkage strain occurs in the saturated phase of drying with an evaporative flux at the surface and a perimeter capillary force. Limiting void ratio and void ratio variation correlate well with surface tension confirming a role of surface capillary forces in the process. Clayey silt is more sensitive to pore fluid properties than granite powder. Hence, clay water evaporation mechanism is of particular interest for further investigation. The shrinkage limit appears also to be controlled by a limitation in skeleton compressibility.

\section{Acknowledgment}

This work is funded by a cooperation of the US NSF (grant \# 0324543) and Swiss NSF (grant 200021-101917).

\section{References}

Abu-Hejleh AN, Znidarcic D (1995) Desiccation theory for soft cohesive soils, J Geotech Eng 121(6):492-502

Croney D, Coleman JD (1954) Soil structure in relation to soil suction (pF), J Soil Sci 5:75-84

Fleureau JM, Kheirbek-Saoud S, Soemitro R, Taibi S (1993) Behavior of clayey soils on drying-wetting paths, Can Geotech J 30(2):287-296

Fredlund DG, Rahardjo H (1993) Soil mechanics for unsaturated soils. WileyInterscience Publication, John Wiley and Sons, Inc.

Hu L, Péron H, Hueckel T, Laloui L (2006) Numerical and phenomenological study of desiccation of soil. In: Lu N, Hoyos LR, Reddi L (eds) Advances in Unsaturated Soil, Seepage, and Environmental Geotechnics, GSP 148 ASCE:166-173

Hu L, Péron H, Hueckel T, Laloui L (2007) Drying shrinkage of deformable porous media: mechanisms induced by the fluid removal. GeoDenver 2007, GSP ASCE (to appear)

Kingery WD, Francl J (1954) Fundamental Study of Clay: XIII, Drying Behavior and Plastic Properties, J Am Ceram Soc 37(12):596-602

Konrad JM, Ayad R (1997) An idealized framework for the analysis of cohesive soils undergoing deesiccation, Can Geotech J 34:477-488

Lloret A, Ledesma A, Rodriguez R, Sanchez MJ, Olivella S, Suriol J (1998) Crack initiation in drying soils. Unsaturated Soils, Pékin, International Academic Publishers, pp 497-502

Péron H, Laloui L, Hueckel T, Hu L (2006) Experimental study of desiccation of soil, In: Proceedings of the Fourth International Conference on Unsaturated Soils, UNSAT 2006: pp 1073-1084

Sridharan A, Venkatappa Rao G (1973) Mechanisms controlling compressibility of clays and the role of the effective stress concept, Géotechnique, 23(3):359-382 
Taibi S (1992) Comportement mécanique et hydraulique des sols partiellement saturés. PhD. Thesis, Ecole Centrale de Paris 